\title{
Nitric oxide, oxygen, and prostacyclin in children with pulmonary hypertension
}

\author{
M I Turanlahti, P O Laitinen, S J Sarna, E Pesonen
}

\begin{abstract}
Objective-To test the vasodilatory response of the pulmonary vascular bed in children with pulmonary hypertension. Design-Prospective dose response study in which the effects of inhaled nitric oxide (NO) are compared with those of oxygen and intravenous prostacyclin.

Patients and interventions-The vasodilator test was performed in 20 patients in whom mean pulmonary artery pressure (PAPm) was $\geqslant 40 \mathrm{~mm} \mathrm{Hg}$ and/or pulmonary vascular resistance index was $\geqslant 4 \mathrm{Um}^{2}$. Haemodynamic effects of inhaled NO $(20,40$, and $80 \mathrm{ppm})$ at a fractional inspired oxygen $\left(\mathrm{FiO}_{2}\right)$ value of 0.3 , pure oxygen, oxygen at $\mathrm{FiO}_{2}$ 0.9-1.0 combined with $\mathrm{NO}$ as above or with intravenous prostacyclin at 10 and $20 \mathrm{ng} /$ $\mathrm{kg} / \mathrm{min}$ were measured.

Result-NO decreased PAPm with a dose response from 20 to $40 \mathrm{ppm}$ (mean change at $40 \mathrm{ppm}-5.50,95 \%$ confidence interval (CI) -7.98 to $-3.02 \mathrm{~mm} \mathrm{Hg}$ ). Maximal decrease in the ratio of pulmonary to systemic vascular resistance was achieved with a combination of NO $80 \mathrm{ppm}$ and oxygen $(-0.18,95 \%$ CI -0.26 to -0.10$)$. Increase in the pulmonary flow index was greatest with pure oxygen in those with an intracardiac shunt $(8.52,95 \%$ CI -0.15 to $17.201 / \mathrm{min} / \mathrm{m}^{2}$ ). Neither NO nor oxygen altered systemic arterial pressure but intravenous prostacyclin lowered systemic arterial pressure and resistance.

Conclusions-NO selectively reduces pulmonary vascular resistance and pressure maximally at $40 \mathrm{ppm}$. Oxygen reduces pulmonary vascular resistance and NO potentiates this reduction without affecting the systemic circulation. Prostacyclin vasodilates the pulmonary and the systemic circulations.

(Heart 1998;79:169-174)
\end{abstract}

Keywords: pulmonary hypertension; nitric oxide; prostacyclin; congenital heart disease; children

Paediatrics, Lund

University Hospital,

Lund, Sweden

E Pesonen

Correspondence to:

Dr Turanlahti, Department of Paediatric Cardiology, Division of Paediatrics, The Hospital for Children and Adolescents, University of Helsinki, Stenbäckinkatu 29, FIN-00290 Helsinki, Finland.

Accepted for publication 7 October 1997 surgery in patients with congenital heart disease increase with pulmonary hypertension. Reactivity to vasodilators in patients with primary pulmonary hypertension correlates with improved survival. ${ }^{2}$ In patients for whom the only surgical option is lung or heart lung transplantation, vasodilator testing may be useful to identify those requiring urgent operation. Several vasodilating agents, such as oxygen, tolazoline, and prostacyclin, have been used to test the vasoreactivity of the pulmonary circulation. $^{3}$ These drugs, however, are not selective pulmonary vasodilators, thereby making interpretation difficult.

Undamaged arterial endothelial cells continuously secrete nitric oxide (NO), which, as an inhalant, seems to be an ideal selective pulmonary vasodilating agent. ${ }^{4-17}$ It is almost immediately inactivated by exposure to haemoglobin. ${ }^{18}$ Thus it affects only the pulmonary vascular bed, which it reaches from lung alveoli, without blood contact. The aim of our study was to compare the pulmonary vasodilator effects of inhaled NO with those of oxygen, and correspondingly, to assess the maximal vasodilatory capacity achieved with a combination of high oxygen concentration and either inhaled NO or intravenously administered prostacyclin.

\section{Patients and methods}

PATIENTS

Ethical approval was obtained from the institutional review board of the children's hospital. Written informed consent was obtained from the patients' parents. Patients (age range from 0.3 to 15.6 years) had greatly raised pulmonary vascular resistance-that is, their pulmonary vascular resistance index (PVRI) was $\geqslant 4$ Wood's units $\times \mathrm{m}^{2}$ and/or their mean pulmonary artery pressure (PAPm) was $>40 \mathrm{~mm} \mathrm{Hg}$. Cardiac catheterisation was performed in 28 children with primary $(n=2)$ or secondary $(n=26)$ pulmonary hypertension. Secondary pulmonary hypertension was a consequence of intracardiac shunts $(n=24)$, vasculitis $(n=1)$, or bronchopulmonary dysplasia and high altitude exposure $(n=1)$. Eight patients were excluded: four with left heart obstruction, two with persistent hypercapnia (one with tracheobronchal malasia and another with pulmonary atelectases), one because of technical problems in monitoring $\mathrm{NO}$ and nitric dioxide $\left(\mathrm{NO}_{2}\right)$ concentrations, and one because of pulmonary hypertensive crisis during the study. One patient who had bronchopulmonary dysplasia and high altitude exposure and a PVRI of $3.8 \mathrm{Um}^{2}$ and PAPm of $19 \mathrm{~mm} \mathrm{Hg}$ was included because the decision to treat with vasodilators was dependent on the responsiveness to studied vasodilators.

Sixteen of the 20 patients studied had a congenital heart defect with left to right shunting. Ten patients with a congenital heart defect had 


\begin{tabular}{|c|c|c|c|c|c|c|c|c|c|c|c|}
\hline & \multirow[b]{2}{*}{$\begin{array}{l}\text { Age (years)/ } \\
\text { sex }\end{array}$} & \multirow[b]{2}{*}{ Diagnosis } & \multirow[b]{2}{*}{ Tris. 21} & \multicolumn{3}{|c|}{$\begin{array}{l}\text { Mean pulmonary artery pressure } \\
(\mathrm{mm} \mathrm{Hg})\end{array}$} & \multicolumn{5}{|c|}{ Pulmonary vascular resistence index $\left(\mathrm{Um}^{2}\right)$} \\
\hline & & & & $\mathrm{FiO}_{2}=0.3$ & $\begin{array}{l}\mathrm{NO} 40 \\
\mathrm{FiO}_{2}=0.3\end{array}$ & $\begin{array}{l}\mathrm{PGI}_{2} 20 \\
\mathrm{FiO}_{2}>0.9\end{array}$ & $\mathrm{FiO}_{2}=0.3$ & $\begin{array}{l}\mathrm{NO} 40 \\
\mathrm{FiO}_{2}=0.3\end{array}$ & $\mathrm{FiO}_{2}>0.9$ & $\begin{array}{l}\mathrm{NO} 40 \\
\mathrm{FiO}_{2}>0.9\end{array}$ & $\begin{array}{l}\mathrm{PGI}_{2} 20 \\
\mathrm{FiO}_{2}>0.9\end{array}$ \\
\hline \multicolumn{12}{|c|}{ Congenital heart disease } \\
\hline 1 & $0.3 / \mathrm{F}$ & ASD VSD & No & 48 & 44 & 42 & 4.3 & 3.3 & 1.6 & 1.3 & 1.4 \\
\hline 2 & $0.3 / \mathrm{M}$ & VSD DORV & No & 55 & 45 & 44 & 2.8 & 2.4 & 0.6 & 0.8 & 0.7 \\
\hline 3 & $0.3 / \mathrm{F}$ & Truncus arteriosus & No & 50 & 37 & 57 & 6.8 & 2.7 & 1.4 & 1.2 & 1.8 \\
\hline 4 & $0.4 / \mathrm{M}$ & ASD VSD & No & 39 & 33 & 25 & 3.8 & 3.3 & 2.7 & 2.9 & 1.6 \\
\hline 5 & $0.4 / \mathrm{F}$ & AVSD & Yes & 50 & 40 & 34 & 6.5 & 4.5 & 2.6 & 3.0 & 3.1 \\
\hline 6 & $0.4 / \mathrm{M}$ & ASD VSD PDA & Yes & 61 & 57 & 66 & 7.3 & 8.1 & 6.5 & 6.2 & 9.5 \\
\hline 7 & $0.4 / \mathrm{F}$ & VSD PDA & Yes & 64 & 71 & 53 & 7.7 & 7.8 & 3.5 & 7.5 & 2.4 \\
\hline 8 & $0.5 / \mathrm{F}$ & VSD PDA & Yes & 41 & 37 & 30 & 2.9 & 2.8 & 2.9 & 2.3 & 1.6 \\
\hline 9 & $0.6 / \mathrm{F}$ & AVSD & Yes & 39 & 37 & 31 & 5.5 & 4.8 & 1.2 & 1.2 & 0.8 \\
\hline 10 & $0.8 / \mathrm{F}$ & VSD & Yes & 41 & 36 & 32 & 2.9 & 2.8 & 2.6 & 1.6 & 1.4 \\
\hline 11 & $1.1 / \mathrm{M}$ & ASD VSD PDA & Yes & 43 & 39 & 47 & 5.4 & 4.0 & 2.9 & 2.8 & 2.6 \\
\hline 12 & $3.0 / \mathrm{F}$ & Multiple VSDs & Yes & 55 & 51 & 56 & 16 & 11.9 & 3.6 & 9.3 & 8.4 \\
\hline 13 & $4.0 / \mathrm{M}$ & AOP window & No & 62 & 61 & 66 & 4.9 & 3.5 & 3.4 & 3.8 & 5.4 \\
\hline 14 & $7.2 / \mathrm{M}$ & $\begin{array}{l}\text { Postop hemitruncus } \\
\text { and VSD }\end{array}$ & No & & 38 & 36 & 81 & 63 & 51 & 51 & 50 \\
\hline 15 & $12.8 / \mathrm{F}$ & VSD & Yes & 54 & 52 & 45 & 8.9 & 10.0 & 7.1 & 6.7 & 6.7 \\
\hline 16 & $13.6 / \mathrm{F}$ & VSD PDA & Yes & 77 & 80 & 76 & 18.1 & 17.3 & 11.6 & 13.0 & 10.1 \\
\hline Mean & 2.9 & & & 52 & 47 & 46 & 7.0 & 6.0 & 3.7 & 4.3 & 4.0 \\
\hline \multicolumn{12}{|c|}{ Other causes of pulmonary hypertension } \\
\hline 17 & $1.1 / \mathrm{F}$ & BPD HAE PH & No & 19 & 18 & 23 & 3.8 & 3.7 & 3.2 & 1.8 & 2.1 \\
\hline 18 & $2.6 / \mathrm{F}$ & $\mathrm{PPH}$ & No & 64 & 65 & 67 & 18.9 & 18.8 & 14.2 & 14.3 & 12.3 \\
\hline 19 & $12.9 / \mathrm{M}$ & $\mathrm{PPH}$ & No & 127 & 125 & 115 & 35.1 & 29.0 & 29.2 & 24.5 & 25.6 \\
\hline 20 & $15.6 / \mathrm{F}$ & SLE PH & No & 29 & 24 & 37 & 12.2 & 7.4 & 9.4 & 8.4 & 6.3 \\
\hline Mean & 8.1 & & & 60 & 58 & 61 & 17.5 & 14.7 & 14.0 & 12.3 & 11.6 \\
\hline
\end{tabular}

AOP window, aortopulmonary window; ASD, atrial septal defect; AVSD, atrioventricular septal defect; BPD, bronchopulmonary dysplasia; DORV, double outlet of right ventricle; HAE, high altitude exposure; PDA, patent ductus arteriosus; PH, pulmonary hypertension; PPH, primary pulmonary hypertension; SLE, systemic lupus erythematosus; VSD, ventricular septal defect.

trisomy 21. Table 1 shows patient data and basic pulmonary measurements.

HAEMODYNAMIC ASSESSMENT

Oxygen consumption was measured before and immediately after catheterisation with a metabolic monitor (Deltatrac; Datex, Engström, Helsinki, Finland). Patients were sedated by a standardised method during catheterisation (ketamine infusion supplemented with fentanyl or isoflurane boluses, or both). Mechanical ventilation with a volume controlled ventilator (Servo; Siemens, Stockholm, Sweden) was used in 17 patients. Endotracheal intubation was facilitated with pancuronium bromide. Three patients were not intubated. The end tidal carbon dioxide concentration was monitored with a capnometer (Datex). Systemic artery pressure was measured noninvasively with a manometer in the upper right arm (Dinamap; Critikon, Tampa, Florida, USA or Symphony N-3000; Nellcor, Pleasanton, California, USA), but also in the radial artery in 18 patients. Heart rate, arterial and venous oxygen saturation, blood gas tension, systemic arterial and venous pressure, and ventricular pressure were recorded at the start of the study. Pulmonary artery pressure and left ventricular end diastolic pressure (14 patients) or pulmonary capillary wedge pressure (six patients) were measured to assess the transpulmonary gradient. Oxygen consumption, measured according to Fick's principle, was used to calculate pulmonary and systemic blood flow.

PROTOCOL FOR THE VASODILATOR TEST

NO (1000 ppm) in nitrogen was administered through a separate flow meter and mixed with air and oxygen near the endotracheal tube or face mask. Inhaled $\mathrm{NO}$ and $\mathrm{NO}_{2}$ concentrations were measured endotracheally in intu- bated patients $(n=17)$ or in the nasopharynx using the electrochemical method (Polytron; Dräger, Germany) $(n=3)$. Arterial and venous saturation and methaemoglobin (metHb) concentration (IL CO-Oximeter 482; Instrumentation Laboratory, Lexington, Massachusetts, USA) were determined.

Response of the pulmonary vascular bed to various vasodilator drugs was tested serially. Before each change there was a washout period of five minutes during which the patient breathed a basic gas mixture: oxygen $(30 \%)$ in nitrogen $(70 \%)$ during the first stage and pure oxygen during the second. In the first stage after baseline measurements NO (20 ppm) was added to inspired gas for five minutes and haemodynamic measurements were repeated at the end of the period. NO inhalation was repeated at doses of 40 and $80 \mathrm{ppm}$. During the second stage the inhaled oxygen concentration was increased to $100 \%$ for 10 minutes and thereafter $\mathrm{NO}$ inhalation was repeated at doses of 20,40 , and $80 \mathrm{ppm}$ for five minutes with pauses of equal length.

The combined effect of high oxygen concentration and prostacyclin (Flolan; Wellcome, London, UK) at doses of 10 and $20 \mathrm{ng} / \mathrm{kg} / \mathrm{min}$ was measured after 10 minutes. Because prostacyclin has a half life of several hours, this vasodilator was given at the end of the protocol and there was no interval between the two doses. Great care was taken to keep respiratory conditions constant between the baseline and the vasodilator test.

STATISTICAL ANALYSIS AND CALCULATIONS Values are expressed as means (SD). Statistical analyses were performed with BMDP statistical software. Analysis of variance (ANOVA) for repeated measures was used to test differences between baseline measurements and those after administration of vasodilating agents and 


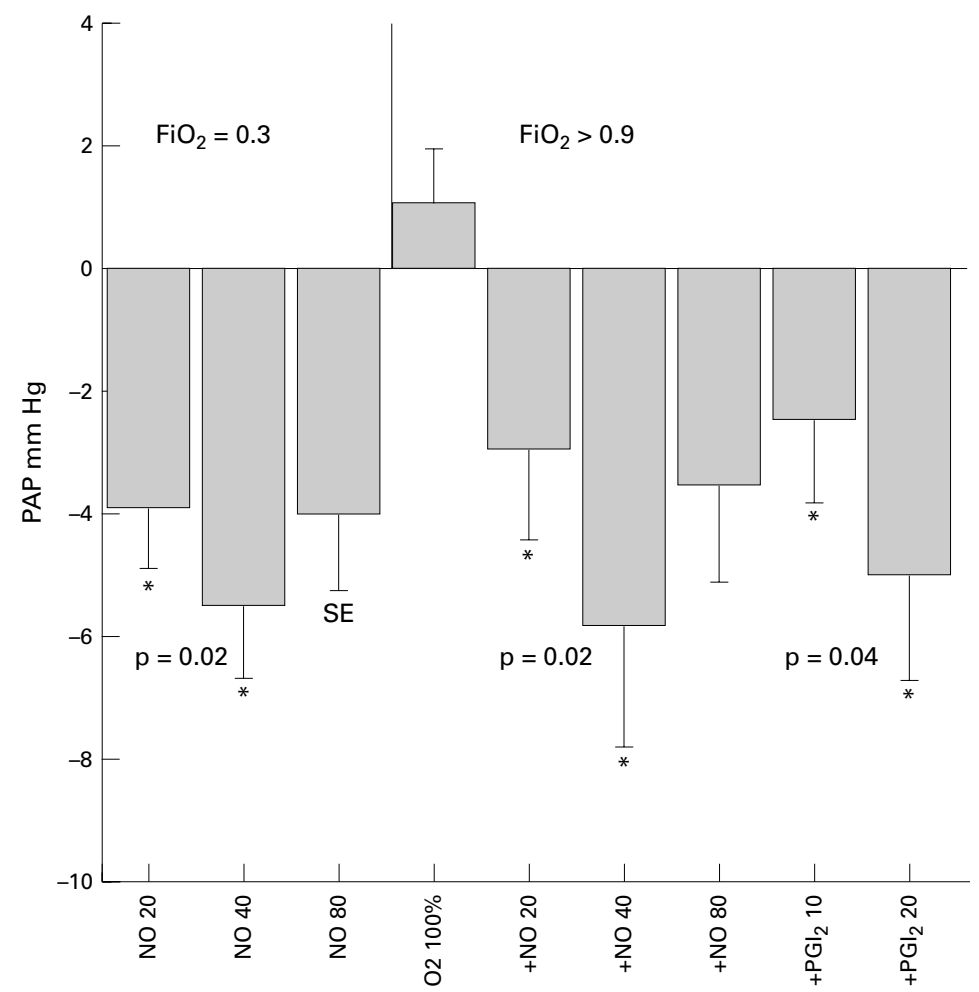

Figure 1 Vasodilator effect on mean pulmonary artery pressure (PAPm). NO, nitric oxide; $\mathrm{PGI}_{2}$ 10, prostacyclin $10 \mathrm{ng} / \mathrm{kg} / \mathrm{min} ; \mathrm{PGI}_{2} 20,20 \mathrm{ng} / \mathrm{kg} / \mathrm{min} ; \mathrm{FiO}{ }_{2}$, fractional inspired oxygen; $\mathrm{O}_{2}$, oxygen. between different doses of these drugs. Stability of the baseline values was also tested. A two dimensional ANOVA was used to detect differences between lower and higher levels of inhaled oxygen. Confidence intervals $(95 \% \mathrm{CI})$ were calculated for main outcome measurements. Regression analysis was used to examine the association between variables. A $p$ value of less than 0.05 was significant.

\section{Results}

BASELINE MEASUREMENTS

Ventilation stability during the study was determined by arterial $\mathrm{pH}$ and the partial pres-

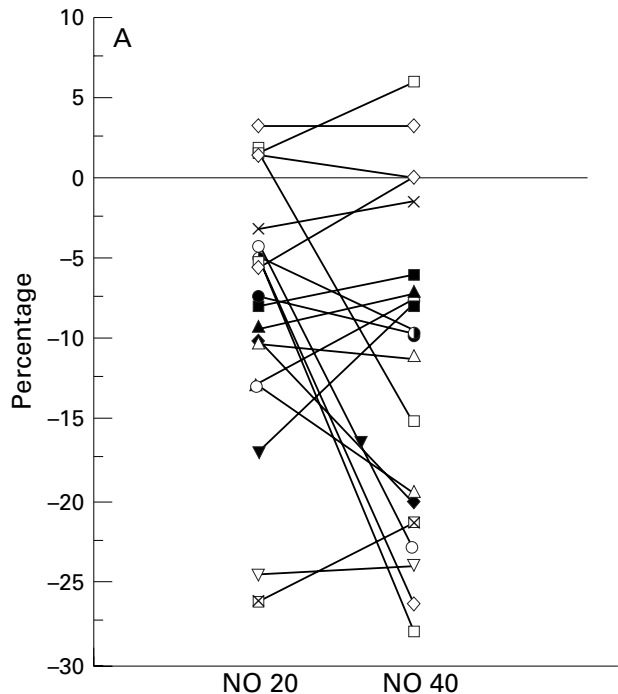

sure of carbon dioxide. At the start of the study the mean (SD) $\mathrm{pH}$ was $7.38(0.05)$ and $\mathrm{pCO}_{2}$ $40.5(5.8) \mathrm{mm} \mathrm{Hg}$. There was no statistical or clinical evidence of conspicuous $\mathrm{pH}$ variation. Three patients who were not intubated had a greater tendency to hypercapnia. Analysis of the $\mathrm{pCO}_{2}$ values using ANOVA, dividing according to the inspired oxygen fraction, however, showed that this variation was not significant $(p=0.07)$.

Oxygen consumption was measured at the start of catheterisation to achieve reliable vascular resistance values (mean value $\left.146.7 \mathrm{ml} / \mathrm{min} / \mathrm{m}^{2}\right)$. There was remarkable variance between individuals (range 94.4$218.0 \mathrm{ml} / \mathrm{min} / \mathrm{m}^{2}$ ), and oxygen consumption was dependent on age $(r=-0.63, \mathrm{p}=0.03)$ and correlated with heart rate $(r=0.66$, $\mathrm{p}=0.015)$. Haemodynamic baseline values were measured and calculated immediately before vasodilator exposure. Baseline stability was tested after dividing the analyses according to oxygen concentration. Instability in the baseline ratio of mean pulmonary to systemic artery pressure occurred only when fractional inspired oxygen $\left(\mathrm{FiO}_{2}\right)$ was $>0.9$.

VASODILATOR EFFECTS ON PULMONARY ARTERY PRESSURE

Responses for NO and prostacyclin were independent of basic oxygen concentration. NO and prostacyclin significantly reduced PAPm; NO reduced PAPm by $5.50 \mathrm{~mm} \mathrm{Hg}$ (95\% CI -7.98 to -3.02$)(p=0.001)$ at the lower oxygen concentration $\left(\mathrm{FiO}_{2}\right.$ 0.3). The decrease was maximal at $40 \mathrm{ppm} ; 80 \mathrm{ppm}$ had no additional effect. Pure oxygen did not alter PAPm. There was a dose-response between the NO doses of 20 and $40 \mathrm{ppm}$ at both oxygen concentrations ( $p=0.02$, ANOVA) and between the prostacyclin doses of 10 and $20 \mathrm{ng} / \mathrm{kg} / \mathrm{min}$ ( $\mathrm{p}=0.04$ ) (fig 1$)$. The individual response at 20 and $40 \mathrm{ppm}$ NO varied. Figure 2 shows the changes from the preceding baseline values.

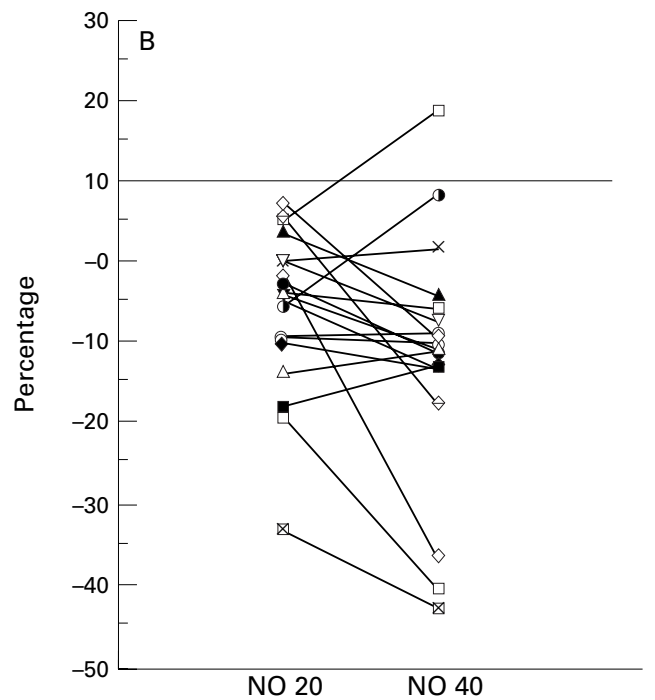

Figure 2 Change (\%) in mean pulmonary arterial pressure (PAPm) from the preceding baseline value at nitric oxide (NO) concentrations of 20 and 40 ppm in all patients $(n=20)$, including non-responders, when the fractional inspired oxygen is $(A) 0.3$ or $(B)>0.9$. 


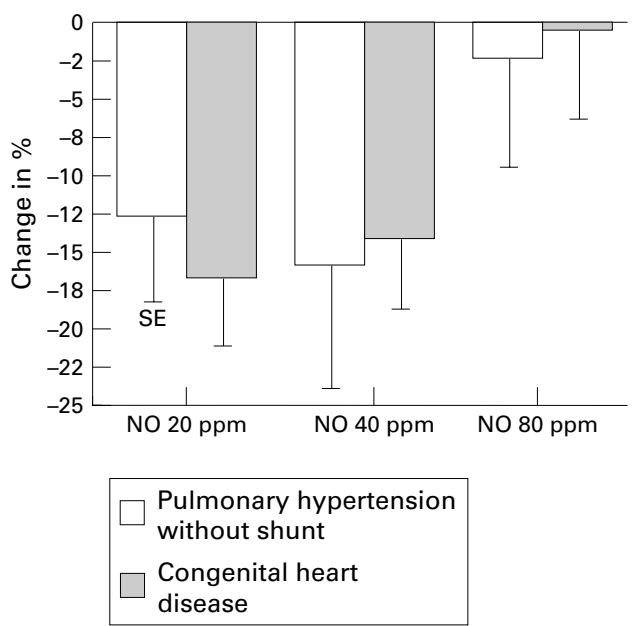

Figure 3 Effect of nitric oxide (NO) on the pulmonary vascular resistance index in patients with pulmonary hypertension and either with $(n=16)$ or without $(n=4)$ left to right shunt.

VASODILATOR EFFECTS ON PULMONARY RESISTANCE

Pure oxygen effectively decreased pulmonary vascular resistance: the PVRI declined by $3.18 \mathrm{Um}^{2} \quad(95 \% \quad \mathrm{CI}-4.80$ to -1.56 , $\mathrm{p}=0.0006)$. There was a negative linear correlation between the effect of oxygen and the basic PVRI $(r=-0.78, \mathrm{p}=0.0003)$ in patients with congenital heart disease $(\mathrm{n}=16)$. The response to inhaled NO at low oxygen concentration was maximal with even the smallest concentration (20 ppm): the PVRI decreased from 9.1 to $7.7 \mathrm{Um}^{2}$ (mean change $-1.37 ; 95 \% \mathrm{CI}-2.37$ to $-0.41, \mathrm{p}=0.007)$. No dose response was seen, and $80 \mathrm{ppm}$ NO had a smaller effect on the PVRI than 20 or $40 \mathrm{ppm}$. Patients with pulmonary hypertension related to other causes than congenital heart defect had initially higher pulmonary vascular resistance, but they still had significant vasodilation (fig 3).

Prostacyclin infusion caused the PVRI to decrease more than with the high fraction of inspired oxygen alone and there was a doseresponse $(\mathrm{p}=0.039)$ : maximum vasodilatation was reached with a dose of $20 \mathrm{ng} / \mathrm{kg} / \mathrm{min}$, as the PVRI decreased from the preceding value by $1.06 \mathrm{Um}^{2}$ (95\% CI -1.95 to -0.17$)$.

SYSTEMIC EFFECTS

The systemic vascular resistance index (SVRI) and systemic vascular pressure were not changed by either adding $\mathrm{NO}$ or increasing the oxygen fraction. Prostacyclin had a strong effect on the SVRI, which decreased by $6.8 \mathrm{Um}^{2}(95 \% \mathrm{CI}-10.20$ to -3.43$)$ with the maximal dose $(\mathrm{p}<0.0001)$. The impact of prostacyclin on the SVRI was dose dependent $(p=0.006)$. The ratio of mean pulmonary to mean systemic artery pressure, however, tended to rise during prostacyclin infusion (fig 4). Most patients had clinical symptoms of systemic hypotension. In many patients prostacyclin also increased the ratio of pulmonary to systemic vascular resistance from the preceding baseline; this change was significant from that of other vasodilators in this study $(\mathrm{p}=0.0002)$.

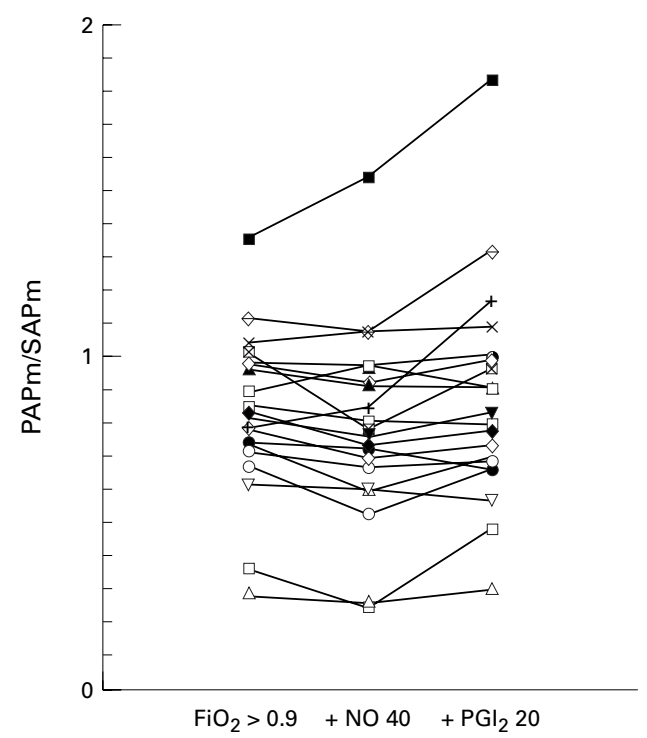

Figure 4 Ratio of mean pulmonary artery pressure $(P A P m) / m e a n$ systemic artery pressure $(S A P m)$ at a nitric oxide (NO) concentration of $40 \mathrm{ppm}$ and a prostacyclin $\left(\mathrm{PGI}_{2}\right)$ dose of $20 \mathrm{ng} / \mathrm{kg} / \mathrm{min}$ when the fractional inspired oxygen $\left(\mathrm{FiO}_{2}\right)$ value is $>0.9$.

The high $\mathrm{FiO}_{2}$ lowered the ratio of pulmonary to systemic vascular resistance from 0.45 to $0.31(95 \%$ CI for the change -0.23 to $-0.05, p=0.0006)$. Maximal decrease in the ratio of pulmonary to systemic vascular resistance was achieved with a combination of NO 80 ppm and oxygen $(-0.18,95 \%$ CI -0.26 to -0.10$)$.

CHANGES IN PULMONARY BLOOD FLOW

The change in inhaled oxygen concentration from $30 \%$ to $100 \%$ led to a significant increase in pulmonary blood flow in 16 patients with left to right shunt (mean change $8.52 ; 95 \% \mathrm{CI}$ -0.15 to $\left.17.20 \mathrm{l} / \mathrm{min} / \mathrm{m}^{2}, \mathrm{p}=0.005\right)$. Neither NO nor prostacyclin increased the effect of high $\mathrm{FiO}_{2}$ on pulmonary blood flow index.

\section{REVERSED ORDER}

Pure oxygen was tested before NO delivery in five additional patients with secondary pulmonary hypertension to examine whether NO sensitises arterial muscle cells to oxygen. There was no evidence of a carry over effect (data not shown).

\section{METHAEMOGLOBINAEMIA}

At the start of the study the mean (SD) metHb concentration was $0.7(0.48) \%$. Maximal NO inhalation $(80 \mathrm{ppm})$ caused a mean (SD) rise to $2.7(1.4) \%$. In the next five minutes the metHb concentration continued to increase to 2.9(1.6)\%. The high $\mathrm{FiO}_{2}$ combined with $\mathrm{NO}$ significantly raised the metHb concentration: a peak value of $3.3 \%$ (mean difference $0.61: 95 \%$ CI 0.33 to $0.89 \%, \mathrm{p}<0.0001$ ) was reached after inhalation of pure oxygen and $\mathrm{NO}$ at 80 ppm for five minutes. Linear regression analysis showed a negative association between this maximal metHb concentration and the logarithm for age $(r=-0.62, \mathrm{p}=0.005)$. 


\section{Discussion}

NO, the endothelium derived relaxing factor, participates in maintaining normal vascular tone in systemic and pulmonary vessels. Endothelium dependent pulmonary artery relaxation is impaired in patients with primary and secondary pulmonary hypertension and after cardiopulmonary bypass. ${ }^{19} 20$ As an inhaled gas NO, a magic bullet, has rapidly become an important option in the treatment of life threatening postoperative pulmonary hypertensive crisis. In patients with congenital heart disease, however, there are only a few clinical trials on the dose response of $\mathrm{NO}$ or comparisons with other vasodilatory drugs. ${ }^{21-25}$

In this study NO was used to assess pulmonary vasoreactivity in patients with either congenital heart disease or evidence of pulmonary vascular disease, or both. Inhaled NO selectively dilated the pulmonary vascular bed without systemic side effects. The dose response of $\mathrm{NO}$ at 20, 40 and $80 \mathrm{ppm}$ was examined; in previous trials concentrations up to $80 \mathrm{ppm}$ have been safe and effective..$^{51322}$ Maximal response was achieved at $40 \mathrm{ppm}$. The effect was potentiated with subsequent oxygen. Prostacyclin acted as a potent vasodilator, affecting the systemic and pulmonary vascular beds.

Prostacyclin was tested only with a $\mathrm{FiO}_{2}$ value of more than 0.9. Prostacyclin at $20 \mathrm{ng} / \mathrm{kg} / \mathrm{min}$ was as effective as $\mathrm{NO}$ at 40 or 80 ppm with oxygen in lowering pulmonary vascular resistance or pressure, but many patients had systemic effects.

DOSE-RESPONSE

The effect of 20 and 40 ppm NO on PAPm showed a dose response, the difference being significant. Pulmonary vascular resistance was changed less by $80 \mathrm{ppm}$ NO than by $40 \mathrm{ppm}$. Maximum vasodilatation with hyperoxia was achieved with $80 \mathrm{ppm}$ NO, but the difference between the response to 40 or $80 \mathrm{ppm}$ was not significant. Our results differ from those of Roberts et $a l,{ }^{22}$ who found that maximum reduction in the PVRI at a $\mathrm{FiO}_{2}$ of $0.21-0.3$ was achieved with $80 \mathrm{ppm}$ NO.

Many of our patients had moderately raised pulmonary vascular resistance (table 1 ). What grade of reactivity is sufficient to guarantee the safety of operating on a patient with congenital cardiac disease and secondary pulmonary hypertension? Linear correlation between basic pulmonary vascular resistance and the vasodilatory effect of oxygen was seen in patients with left to right shunting and secondary changes in pulmonary circulation. One patient with primary pulmonary hypertension and both pulmonary pressure and resistance higher than corresponding systemic values was able to react with considerable vasodilatation (patient number 19 , table 1). Vasodilatation is usually absent or weak when there is a very high ratio of pulmonary to systemic vascular resistance. The decrease in pulmonary vascular resistance or pressure in patients with intracardiac shunts did not differ from that in those with pulmonary hypertension due to other aetiology.
SIDE EFFECTS OF NITRIC OXIDE

metHb and formation of $\mathrm{NO}_{2}$ are side effects of treatment with NO. ${ }^{26-29} \mathrm{An}$ association between age and increased metHb concentrations was found. Hyperoxia combined with $80 \mathrm{ppm} \mathrm{NO}$ clearly raised the metHb percentage, but the short exposure time limited metHb formation. The rise in metHb concentration was about $2.0(1.2) \%$. Exposure to latent free radicals formed by NO through its unpaired electron is a potential danger. $\mathrm{NO}$ concentrations greater than $80 \mathrm{ppm}$ cause a rapid increase in $\mathrm{NO}_{2}$ formation $^{28}{ }^{29}$ and nitrous and nitric acids are consequently formed. In our study, however, $\mathrm{NO}_{2}$ was kept within the reported safety limit of $5 \%$. A high oxygen concentration accelerated $\mathrm{NO}_{2}$ formation in our patients, as was also found by Foubert et al. ${ }^{29}$

\section{CLINICAL IMPLICATIONS}

$\mathrm{NO}$ as a gaseous vasodilator is easy to administer. Selectivity of the pulmonary circulation allows inhaled $\mathrm{NO}$ at low concentrations to be considered as a safe and reliable vasodilator in patients with congenital heart disease. NO inhalation was not administered in patients with heart defects associated with mitral or aortic stenosis. Pulmonary oedema is a possible consequence in those with obstructions in the left heart. Inhaled NO might be useful in evaluating the vasodilating capacity of patients with primary hypertension. Lack of reactivity may indicate a poor prognosis and the need for early lung or heart lung transplantation. One of the advantages of $\mathrm{NO}$ in cardiac catheterisation is its short half life. The haemodynamic effects of $\mathrm{NO}$ on the pulmonary circulation are more obvious than those of prostacyclin, which may dilate systemic arteries even more than pulmonary vessels. Unlike oxygen, inhaled NO, in addition to increasing pulmonary flow, is able to reduce pulmonary arterial pressure. Maximal decrease in pulmonary vascular pressure was achieved with an inhaled NO concentration of $40 \mathrm{ppm}$.

Recommendations for preoperative vasodilator testing are: to assess the effect of pharmaceutical treatment on pulmonary artery pressure $40 \mathrm{ppm}$ should be delivered for five minutes followed by pure oxygen for 10 minutes; and to quantify maximum vasodilatation $40 \mathrm{ppm}$ NO should be added to the high oxygen concentration for five minutes. Preoperative testing with NO in patients with intracardiac shunts and secondary pulmonary hypertension may prove useful in evaluating operability. Moreover, patients with clearly raised but reactive pulmonary vascular resistance should be given the possibility of NO treatment immediately after bypass in the operating theatre.

This study was supported by grants from the Finnish Foundation for Cardiovascular Research and the Foundation for Pedition for Research, Helsinki, Finland, and AGA AB Medical atric Research, Helsinki, Finlan
Research Fund, Lidingö Sweden.

1 Hopkins RA, Bull C, Haworth SG, et al. Pulmonary hypertensive crisis following surgery for congenital heart defects in young children. Eur $\mathcal{F}$ Cardiothorac Surg 1991;5:628-34.

2 Houde C, Bohn DJ, Freedom RM, et al. Profile of paediatric patients with pulmonary hypertension judged by responsiveness to vasodilators. Br Heart $\mathcal{F}$ 1993;70:461-8. 
3 Bush A, Busst C, Booth K, et al. Does prostacyclin enhance the selective pulmonary vasodilator effect of oxygen in children with congenital heart disease? Circulation 1986;74: 135-44.

4 Pepke-Zaba J, Higenbottam T, Dinh-Xuan A. Inhaled nitric oxide as a cause of selective pulmonary vasodilatation in pulmonary hypertension. Lancet 1991;338:1173-4.

5 Haydar A, Mauriat P, Pouard P, et al. Inhaled nitric oxide for postoperative pulmonary hypertension in patients with congenital heart defects. Lancet 1992;340:1545.

6 Roberts JD Jr, Polaner DM, Lang P, et al. Inhaled nitric oxide in persistent pulmonary hypertension of the newoxide in persistent pulmonary
born. Lancet 1992;340:818-19.

7 Kinsella JP, Neish SR, Shaffer E, et al. Low-dose Kinsella JP, Neish SR, Shaffer E, et al. Low-dose inhalational nitric oxide in persistent pulmonary
sion of the newborn. Lancet 1992;340:819-20.

8 Frostell C, Fratacci M-D, Wain JC, et al. Inhaled nitric oxide- a selective pulmonary vasodilator reversing hypoxic pulmonary vasoconstriction. Circulation 1991;83:2038-46.

9 Fratacci $M-D$, Frostell $C$, Chen $T$, et al. Inhaled nitric oxide - a selective pulmonary vasodilator of heparinprotamine vasoconstriction in sheep. Anesthesiology 1991; 75:990-9.

10 Berner M, Beghetti M, Ricou B, et al. Relief of severe pulmonary hypertension after closure of a large ventricular
septal defect using low dose inhaled nitric oxide. Intensive Care Med 1993;19:75-7.

11 Frostell CG, Blomqvist H, Hedenstierna G, et al. Inhaled nitric oxide selectively reverses human hypoxic pulmonary vasoconstriction without causing systemic vasodilatation. Anesthesiology 1993:78:413-16.

12 Girard C, Lehot J-J, Pannetier J-C, et al. Inhaled nitric oxide after mitral valve replacement in patients with chronic pulmonary artery hypertension. Anesthesiology 1992;77:880-3.

13 Adatia I, Perry S, Landzberg M, et al. Inhaled nitric oxide and hemodynamic evaluation of patients with pulmonary hypertension before transplantation. 7 Am Coll Cardiol 1995;25:1656-64.

14 Beghetti M, Habre W, Friedli B, et al. Continuous low dose inhaled nitric oxide for treatment of severe pulmonary hypertension after cardiac surgery in paediatric patients. $B r$ hypertension after cardic

15 Berner M, Beghetti $M$, Spahr-Schopfer I, et al. Inhaled nitric oxide to test the vasodilator capacity of the pulmonary vascular bed in children with long-standing pulmonary hypertension and congenital heart disease. $A m$ 7 Cardiol 1996;77:532-5.

16 Pearl RG. Inhaled nitric oxide: the past, the present and the future. Anesthesiology 1993;78:413-16.

7 Winberg P, Lundell BPW, Gustafsson LE. Effect of inhaled nitric oxide on raised pulmonary vascular resistance in children with congenital heart disease. Br Heart 7 1994;71: 282-6.

18 Chiodi H, Mohler JG. Effects of exposure of blood hemoglobin to nitric oxide. Environ Res 1985;37:355-63.

19 Celermajer DS, Cullen S, Deanfield JE. Impairment of endothelium-dependent pulmonary artery relaxation in children with congenital heart disease and abnormal pulmonary hemodynamics. Circulation 1993;87:440-6.

20 Dinh-Xuan AT, Higenbottam TW, Clelland C, et al. Impairment of pulmonary endothelium-dependent relaxation in patients with Eisenmenger's syndrome. $\mathrm{Br} f$ Pharmacol 1989;99:9-10.

21 Miller OI, Celermajer DS, Deanfield JE, et al. Very-low-dose inhaled nitric oxide: a selective pulmonary vasodilator after operations for congenital heart disease. $\mathcal{F}$ Thorac Cardiovasc operations for congenital
Surg 1994;108:487-94.

22 Roberts JD Jr, Lang P, Bigatello LM, et al. Inhaled nitric oxide in congenital heart disease. Circulation 1993;87:44753.

23 Bigatello LM, Hurford WE, Kacmarek RM, et al. Prolonged administration of low concentrations of nitric oxide in patients with severe adult respiratory distress syndrome. Anesthesiology 1994;80:761-70.

24 Kieler-Jensen N, Ricksten SE, Stenqvist O, et al. Inhaled nitric oxide in the evaluation of heart transplant candidates with elevated pulmonary vascular resistance. 7 Heart Lung Transplant 1994;13:366-75.

25 Goldman AP, Delius RE, Deanfield JE, et al. Nitric oxide is superior to prostacyclin for pulmonary hypertension after cardiac operations. Ann Thorac Surg 1995;60:300-5.

26 Adatia I, Wessel DL. Therapeutic use of inhaled nitric oxide. Curr Opin Pediatr 1994;6:583-90.

27 Moncada S, Palmer RMJ, Higgs EA. Nitric oxide: physiology, pathophysiology, and pharmacology. Pharmacol Rev 1991;43:110-42.

28 Miller OI, Celermajer DS, Deanfield JE, et al. Guidelines for the safe administration of inhaled nitric oxide. Arch Dis Child 1994;70:F47-9.

29 Foubert L, Fleming B, Latimer R, et al. Safety guidelines for use of nitric oxide. Lancet 1992;339:1615-16. 